sions. This view is difficult to reconcile with the rapid entry of the injecting fluids, and the result of further injection experiments is to suggest that many wood elements in tension contain water vapour. Such elements, when water is available, will readily fill with water again. These observations do not solve the problem of the ascent of sap in tall trees, but they do suggest it is ripe for reconsideration. They also remind us that the buds and branches at a great height always obtain their water by a machinery that is only set in motion by their own growth.

Similarly it may be pointed out that the downward movement of food in the tree-a movement that is usually associated with the bast-seems to be linked with the growth of the bast. This tissue is also formed from the cambium, its formation beginning in the leaf, whence the process spreads gradually down the branches to the trunk and the roots; and the spread of this process of growth synchronises with the time at which a gain of dry weight takes place in the lower regions of the tree. If an attempt is made to estimate the amount of transfer of substance involved in the formation of the new tissues from the cambium, this downward. progressing growth process evidently largely accounts for the movement of substance that takes place. It is clearly impossible to dissociate the problem of transport in the tree from the processes of growth.

\title{
Measurements of Solar Radiation *
}

$\mathrm{T}^{\mathrm{B}}$ HE work of the Smithsonian Institution's Astrophysical Observatory during the decade 1920-30 is described in vol. 5 of its Annals, recently published after an interval of ten years since the appearance of the preceding volume. To assist the reader in forming a proper perspective view of the work, the volume is prefaced by a brief description of the long research on solar radiation undertaken by the Observatory, first under Langley, and later under Dr. C. G. Abbot. It forms an impressive account of a great investigation, of fundamental importance to meteorology, in which the Smithsonian Institution has been the pioneer and praotically the sole worker. The latter is to be regretted, since it is desirable to have independent determinations of so important a quantity as the sun's radiation. There is fortunately no doubt, however, as to the substantial accuracy of the mean Smithsonian value of the 'solar constant'.

One decisive result has emerged from the work of the Observatory, as a consequence of gradual improvements both in the instruments and methods of observation, and in the understanding and reduction of the measurements. It is that the sun's radiation, as it reaches the outside of the earth's atmosphere, and after correction to the mean distance of the earth from the sun, is constant within very narrow limits. At earlier stages of the work the Smithsonian view was contrary to this ; it was contended that the observations showed variability over a range often exceeding five per cent ; the supposed variations ranged over several per cent in the course of years, and showed correlation with the sunspot period; there were also variations over short periods of a few days, which were believed to be confirmed by independent observations for more than fifty days at Bassour in Algeria and Mount Wilson in California. Important consequences for terrestrial weather and weather forecasting were inferred from these results.

In the present volume an account is given of the establishment and progress of several solar radiation observatories, located on mountain tops in

- Annsis of the Astrophysical Observatory of the Smithsonian Institution. Vol. 5 (Pub. No. 8121), By C. G. Abbot, L. B. Aldrich,

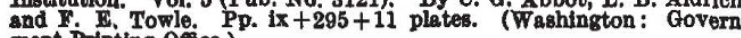
ment Printing Ofice.) desert lands, at which a daily record of the sun's radiation is attempted, both as received at ground level, and as inferred after allowing for atmospheric absorption. The conclusion is reached that " the earlier impression [of considerable solar variations] is not supported ". "We incline to think that the earlier impressions of a larger solar variability were founded on measurements too much affected by terrestrial atmospheric influences. A residuum of apparent solar variation remains, nevertheless, after making all possible improvements. Comparison of results of remote stations; correlations with other measurements independently made by other observers; and especially correlations with weather changes at remote stations, all incline us to consider present indications of solar variation as largely real" (p. 5). The average deviation of the solar constant as measured at a single station on a single day is given (p. 244) as 0.29 per cent, the probable error being 0.24 per cent, as derived by comparing the measurements of the best station (Montezuma, Chile) with those made at Table Mountain (1926-30).

These changes are very small, and in view of the great difficulties involved in correcting accurately for atmospheric absorption, a proof of real solar variability must, as is stated, be very difficult. Comparison of the variations recorded at Monte. zuma and Table Mountain, in cases where satis. factory daily observations occurred consecutively at both stations simultaneously over intervals of ten days or longer, is thought, on the whole, to show a great similarity in the march of the curves, though there are instances of great dissimilarity. But it is pointed out that in these intervals solar changes exceeding 1.5 per cent are rarely indicated.

My own impression, after reflecting on the observational difficulties, the possibility of accidental agreements between the changes at different stations, and the past history of the research, is that the reality of these small variations is not proved. To establish them, much better evidence is required in the form of long-continued observa. tions at different stations, and also independent determinations by different methods at the same station. The correlations with other measurements, and especially with weather changes, which 
are mentioned as accessory evidence in the above quotation, seem beside the point; indeed, they prompt doubts as to the soundness of the discussion and interpretation of the data, doubts which are strengthened by the description of the methods used for determining alleged periodicities in the small observed variations of the solar constant. This part of the text is taken substantially from Dr. Ábbot's paper of 1931, entitled "Weather Dominated by Solar Changes ", the main thesis of which has not carried conviction with most meteorologists. On this point, I am in agreement with Dr. Kimball, who, in the Monthly Weather Review (Dec. 1931, p. 479), wrote, " Is it rational to believe that these major weather changes are caused and explained by alleged short-period changes of less than 1 per cent on the intensity of solar radiation? A part, if not all, of this 1 per cent variation must be set off as caused by inevitable accidental errors, but even if the whole of it were real solar change, can we believe that if this small variation were to cease our major weather changes would disappear also?"
I would regret, however, to end this review on a critical note. The answer to doubts as to the solar variations will be afforded by observations which the Astrophysical Observatory is continuing, and by others for which it makes an earnest plea. While Dr. Abbot states that even the best present data, from Montezuma, fall just short of the accuracy that is required, he adds that there is good hope of making several improvements which should appreciably diminish the experimental error at all the stations.

Besides the main work relating to daily observations of the solar constant, the volume includes an account of the study of the distribution of radiation in the solar spectrum, particularly in the ultra-violet and infra-red regions not covered by the daily solar observations. One interesting and unlooked-for result of the Smithsonian work was the determination of the ozone content of the atmosphere above certain stations, from the yellow-green atmospheric transmission coefficients.

S. Chapman.

\section{A Bibliography of Boyle}

BIBLIOGRAPHY' is a word which has many meanings. The merely enumerative cataloguing of books is the least; their discrete anatomies a higher; and highest of all is their comparative anatomy, working on from detailed observation through steps of induction and verification as rigidly and delightfully scientific as any man of science could desire. But the aims of those who practise in these loftier realms are not always single. On one hand, the pure bibliographer has for his aim the discovery of bygone methods in the various crafts of book-making; to him the matter in the volumes which he studies is no more than the ' copy' supplied to a compositor, and the mind of the author-except inasmuch as its vagaries may cause disturbances in proof, and produce variant issues-exists as a remote First Cause, beyond inquiry. How much of the archæology of the greatest art in civilisation has been discovered by such students is recognised only vaguely, even by some of the historians who might make use of it. The literary bibliographer, on the other hand, has a different aim; his primary interest in a series of books is in their author (or a group of authors); yet even he wins little enough sympathy from most of us, who are content with the innocent rôle of gentle reader.

It will be seen that the bibliographer is a lonely soul as a rule; and if he strays beyond the warmth of his own eircle, the wind of the world blows past him chilly and comfortless. No wonder that he and his kind have hitherto purposely shunned contact with students of the impersonal arts of Nature, who outside their circle are supposed to be inhumanly heedless of persons and the past, and regardful only of things and the present. There have been, nevertheless, bibliographies (in the full sense) of scientific work : usually, however, according to subjects-such as Mr. James Henderson's
"Bibliotheca Taqularum Mathematicarum"-or of a library, such as Ferguson's well-known work on the Young chemical collection. Of bibliographies of single scientific authors there must hitherto have been very few that would satisfy bookmen as well as men of science. However, the collector's enthusiasm of the late Sir William Osler for medical works set a vogue in this field, and so it was not surprising that William Harvey was the subject of the first true bibliography of a seventeenth century scientific worker, produced a few years ago by Mr. G. L. Keynes. Now a kindred interest has inspired Prof. J. F. Fulton, lately fellow of Magdalen College, Oxford, and now professor in the School of Medicine at Yale, to undertake a larger and very difficult task: the bibliography of Robert Boyle.*

Let it be said at once that Prof. Fulton has carried out the task with particular success, happily conjoining the functions of both types of bibliographer. He has not only used the resources of a score or so of great libraries in Great Britain and on the Continent, but he has also achieved the rare privilege of being himself the owner of at least one copy of very nearly every work, edition, issue, and variant that comes within the wide scope of his title. The unrestricted opportunities for close examination and repeated reading which this has given him show, by their results in this volume, the honourable side of book-collecting; and the scientific historian (or, more probably, the group of them) who may some day try to set before us Boyle's contributions to knowledge, will be deeply in Prof. Fulton's debt.

In Section $A$ are described forty-two distinct and self-contained works by Boyle, first printed between

* Proceedings and Papers of the Oxford Bibliographical Society, vol. 3 , pt. 1, pp. 1-172. "A Bibliography of the Honourable Robert Boyle, Fellow of the Royal Society", by J. F. Fulton. (Oxford: University Press.) 108 . 